\title{
Excitatory and inhibitory effects of free reinforcers
}

\author{
MARVIN Z. DELUTY \\ Brown University, Providence, Rhode Island 02912
}

\begin{abstract}
Rats' responding was maintained on a random-interval 1-min food schedule. In addition, noncontingent pellets were delivered, independently of the animals' behavior, at either fixed intervals (Experiment 1) or at random intervals (Experiment 2). As the rate of delivery of the periodic and aperiodic free reinforcers increased, the rate of responding decreased. But these free reinforcers, in addition to having this inhibitory effect, had also a local excitatory effect upon responding: leverpressing increased to a level above its mean rate following the delivery of a free food pellet. The time course of this behavioral aftereffect of free reinforcers, for both fixed and random intervals, was dependent upon the proportion of the interval between successive free food deliveries. The relation of these results to those obtained with response-contingent reinforcement, free punishment, and in schedule-induced phenomena is discussed.
\end{abstract}

If the rate of reinforcement for a pigeon's keypecking remains constant, then increases in the rate of other sources of reinforcement result in descreases in responding (Catania, 1963; Rachlin \& Baum, 1972). Such interactions have typically been examined in a choice situation wherein responding on two keys is maintained on concurrent schedules of reinforcement (cf. Catania, 1963, 1966). But such interactions may also be studied where there is only a single key or lever. Rachlin and Baum (1972) reinforced keypecks according to a variable-interval schedule. In one phase of their experiment, additional food was delivered, independently of responding, according to various variable-time (cf. Zeiler, 1968 ) schedules. The rate of keypecking decreased with increases in the rate of these response-independent reinforcers (see also Nevin, 1974).

The purpose of the present study was to examine the time course of the behavioral aftereffect of free reinforcers. In both experiments, responding was maintained on a random-interval (RI) schedule. In addition, extra pellets were delivered, independently of the animal's responding, at either periodic intervals (Experiment 1) or at aperiodic intervals (Experiment 2).

\section{EXPERIMENT 1}

\section{Method}

Subjects. Four male, naive albino Norway rats of the Charles River CD strain served as subjects. Each rat was given a daily ration of $14 \mathrm{~g}$ of ground Purina Chow mixed with $25 \mathrm{cc}$ of water. Water wạs always available in each rat's cage.

Apparatus. Four chambers each had inside dimensions of

This research was supported by NSF Grant GB-43208 to Russell M. Church. The author wishes to thank Dr. Church for his aid and criticism. Requests for reprints should be sent to Marvin Deluty, Department of Psychology, Brown University, Providence, Rhode Island 02912.
$23.2 \times 20.3 \times 21.9 \mathrm{~cm}$. The floors consisted of 16 stainless steel bars, adjacent bars being $1.5 \mathrm{~cm}$ apart. The front and back were made of aluminum; the two sides and the top were made of transparent acrylic. A stainless steel lever $(5.1 \mathrm{~cm}$ wide, $1.3 \mathrm{~cm}$ thick, and $5.1 \mathrm{~cm}$ above the floor) was located in the center of the front wall. Each chamber was enclosed within an ice chest containing a blower, an acrylic window on the side, a pellet dispenser, and a $7.5-\mathrm{W}$ lamp. The reinforcers were $45-\mathrm{mg}$ Noyes food pellets. Leverpresses of at least $.25 \mathrm{~N}$ were recorded. A time-shared PDP-12 computer controlled each phase of the experiment and collected the data.

Procedure. Following magazine training and the shaping of the leverpress response, responses were reinforced according to an RI $1-\min$ food schedule for 20 sessions. The probability of food being primed was $1 / 600$ in each .1-sec interval. Once a response-dependent reinforcer was primed, it remained available until collected. Afterwards, responding continued to be reinforced on the RI 1-min schedule, but additional pellets were delivered, regardless of the rat's behavior, according to various FT $x$-sec schedules. A single pellet was delivered every $x$ sec throughout the 1-h session. The delivery of a free pellet was accompanied by a $.5 \mathrm{sec}$ burst of white noise of approximately $70 \mathrm{~dB}$ (re .0002 dynes $/ \mathrm{cm}^{2}$ ). For all animals, the sequence of the FT schedules and the number of sessions at each condition were the same: FT $30 \mathrm{sec}$ (20 sessions), FT $60 \mathrm{sec}$ (10 sessions), FT $120 \mathrm{sec}$ (20 sessions), FT $45 \mathrm{sec}$ (10 sessions), and finally FT $75 \sec (10$ sessions), i.e., 120, 60, 30,80 , and 48 free pellets per hour, respectively.

\section{Results}

Figure 1 shows the normalized response rate as a function of the rate of free food delivery. For each animal, the mean response rate of the last five sessions of each condition was calculated. The median normalized response rate at each condition was then determined using the formula $\mathrm{B} / \mathrm{A}$, where $\mathrm{B}$ is the response rate from the particular condition and $A$ is the response rate of the last five sessions of the baseline condition. Responding clearly decreased as the rate of free food delivery increased. A repeated measures analysis of variance revealed a significant effect of free reinforcers, $\mathrm{F}(4,12)=3.5, \mathrm{p}<.05$. 


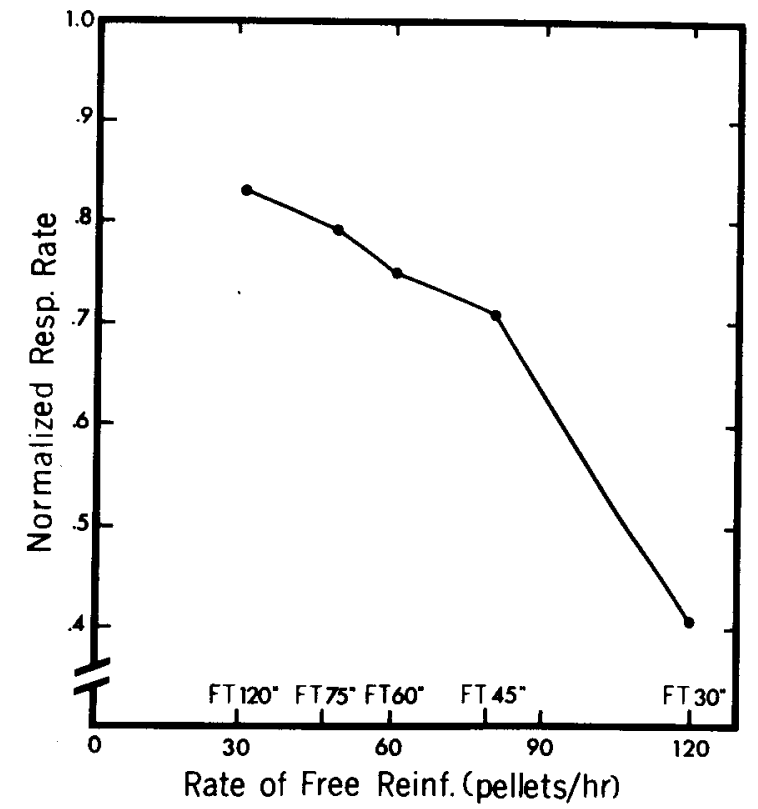

Figure 1. Normalized response rate as a function of the rate of free food delivered according to the FT schedules. Responsedependent food was always delivered on an RI 1-min schedule.

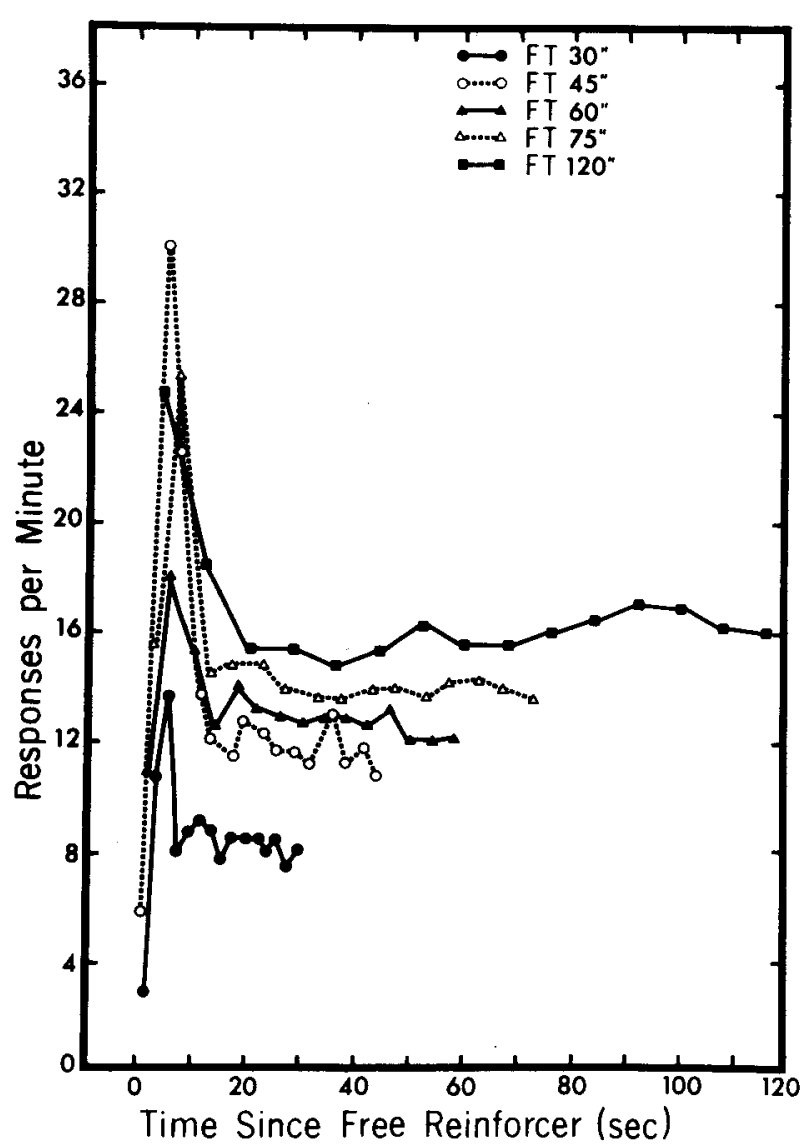

Figure 2. Rate of responding as a function of the time since the delivery of a free pellet during the FT schedules.
Figure 2 shows the rate of responding as a function of the time since the delivery of a free pellet during the FT schedules. At every condition, for each animal, the mean rate of the last five sessions for each of the 15 time bins was calculated. The group median response rate for each of the bins at each condition was then determined. The order of the response gradients was dependent upon the rate of free reinforcer delivery. For the most frequent free-food rate condition (FT $30 \mathrm{sec}$ ), the gradient was at the bottom; for the least frequent freefood rate condition (FT $120 \mathrm{sec}$ ), the gradient was at the top. For all of the FT conditions, responding reached a maximum soon after the delivery of a free pellet, and then decreased for a period of time thereafter before stabilizing. These results were typical of the individual subjects as well, as shown in Figure 3 for one animal.

Figure 4 shows the group median momentary response rate relative to the mean response rate for a condition as a function of the proportion of the fixed interval between successive free pellets. Values along the ordinate that are greater than 1.0 indicate that responding exceeded the mean response rate for that condition; values less than 1.0 indicate that responding was less than the mean response rate. It was assumed that the temporal distributions of Figure 2 emerged following about $4 \mathrm{sec}$ between the delivery of a free pellet, its ingestion by the rat, and the resumption of responding. The proportion of the fixed interval in Figure 4 was, therefore, calculated beginning at $4 \mathrm{sec}$ following the delivery of a free pellet. When the response gradients were plotted in proportional units of the fixed interval, they fell close together. Following the delivery of a free pellet, responding exceeded the mean response rate for the particular condition, and then decreased thereafter. Again these results were also typical of the individual subjects, as shown in Figure 5 for one animal.

\section{EXPERIMENT 2}

\section{Method}

Subjects and apparatus. Four male, naive albino Norway rats of the Charles River CD strain served as subjects. The daily ration and the apparatus were the same as in Experiment 1.

Procedure. Following magazine training and the shaping of the leverpress response, leverpresses were reinforced according to an RI 1-min food schedule for 20 sessions. Thereafter, responding continued to be reinforced on the RI 1-min schedule. But additional pellets were delivered, independently of the rat's behavior, according to a random-time (RT) 30 -sec schedule (20 sessions) and then an RT 60-sec schedule (10 sessions), i.e., 120 and 60 pellets per hour, respectively. A session was $1 \mathrm{~h}$ long. During the RT $30-\mathrm{sec}$ schedule, the probability of a free pellet being primed in each .1 sec was $1 / 300$; during the RT 60-sec schedule, the probability of a free pellet being primed in each $.1 \mathrm{sec}$ was $1 / 600$. The time between two successive free pellets was an exponential waiting time distribution. The delivery of a free pellet was accompanied by a .5 -sec burst of white noise of approximately $70 \mathrm{~dB}$ (re .0002 dynes $/ \mathrm{cm}^{2}$ ). During the final stage of the experiment, to determine if the behavioral aftereffect of free reinforcers was dependent upon the presence 


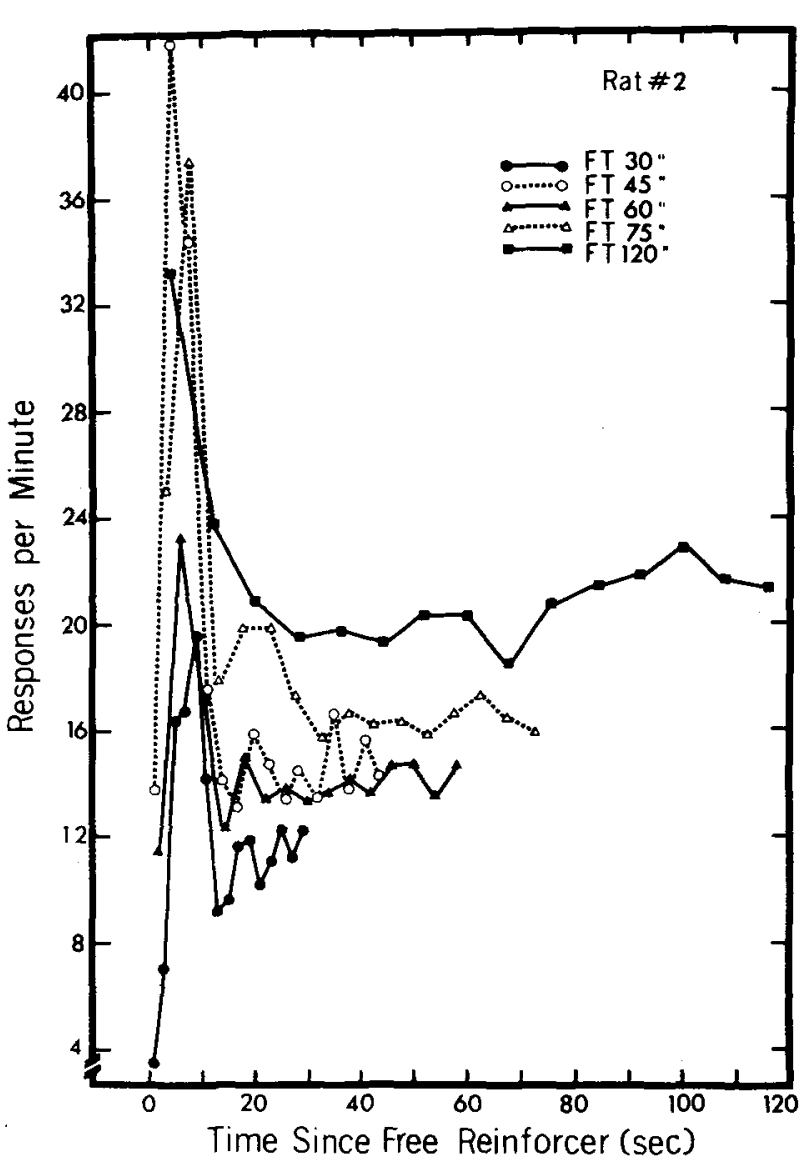

Figure 3. Rate of responding as a function of the time since the delivery of a free pellet during the FT schedules for Rat 2.

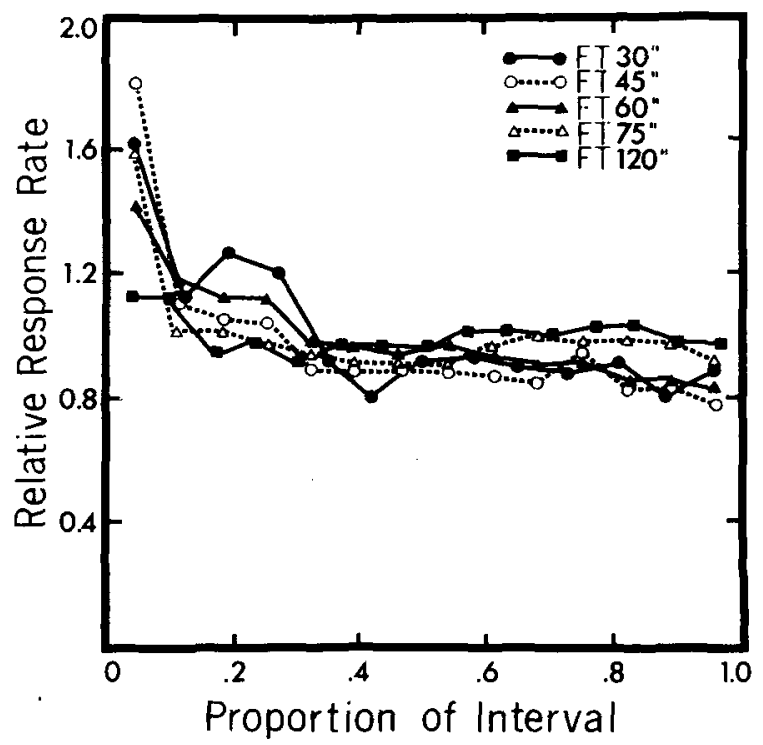

Figure 4. Momentary response rate relative to the mean response rate as a function of the proportion of the periodic interval between successive free pellets. of the white noise, the RT 60-sec schedule condition was repeated for 14 sessions, with the noise not being delivered.

\section{Results}

For each animal, the mean response rate of the last five sessions of each condition was calculated. The median normalized response rate was .84 for the RT 30-sec condition and 1.01 for the RT 60-sec condition. A repeated measures analysis of variance revealed a significant free reinforcer effect, $F(1,3)=$ $16.7, \mathrm{p}<.05$.

Data were collected only for $60 \mathrm{sec}$ following free pellet delivery during the RT 30 -sec condition and for $120 \mathrm{sec}$ following free pellet delivery during the $60-\mathrm{sec}$ condition, although a free pellet could be presented at a time that was greater than twice the mean interval. Figure 6 shows the rate of responding as a function of the time since the delivery of a free pellet during the RT schedules. For each animal, at every condition, the mean rate of the last five sessions for each of the 30 time bins was calculated. The group median response rate for each of the bins at each condition was then determined. Responding reached a maximum soon after the delivery of a free pellet, and then decreased until the delivery of the next free pellet. The response gradients for one animal, as shown in Figure 7, indicate that this was also the case for individual subjects. This pattern of responding occurred, as well, even when the delivery of a free pellet was not accompanied by the burst of white noise.

Figure 8 shows the group median momentary response rate relative to the mean response rate for a condition as a function of the proportion of the random interval between successive free pellets. As was the case for Figure 4, the proportion of the random interval in Figure 8 was calculated beginning at $4 \mathrm{sec}$ following the delivery of a free pellet. Again, as was the case for the periodic interval, when the response gradients were plotted in proportional units of the aperiodic interval, they fell close together. Responding exceeded the mean response rate for a particular condition after the delivery of a free pellet, and then decreased to below the mean rate. Again these results were also typical of the individual subjects, as shown in Figure 9 for one animal.

\section{GENERAL DISCUSSION}

Catania (1973) presented evidence indicating that while response-dependent reinforcers have primarily an excitatory or strengthening effect upon responding, as we expect, there is also a "self-inhibiting" or suppressive effect of such reinforcers upon keypecking. Because, however, of the far greater excitatory effect of the response-contingent reinforcers, this inhibitory effect is typically masked or overshadowed. The present study has shown a mirror relation with respect to responseindependent reinforcers. The primary effect of such non- 


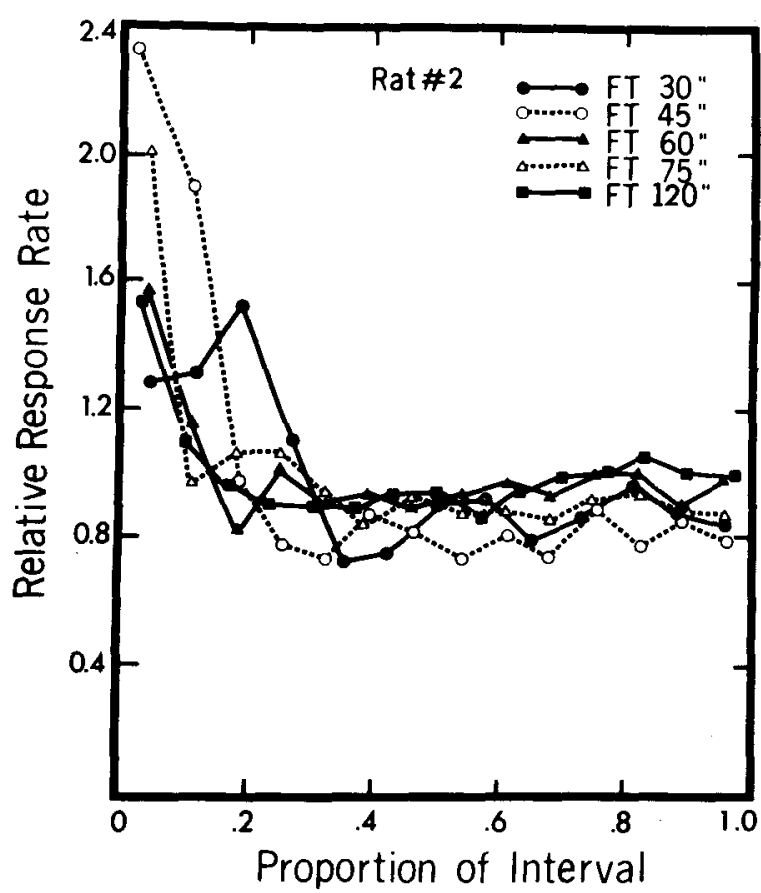

Figure 5. Momentary response rate relative to the mean response rate as a function of the periodic interval between successive free pellets for Rat 2.

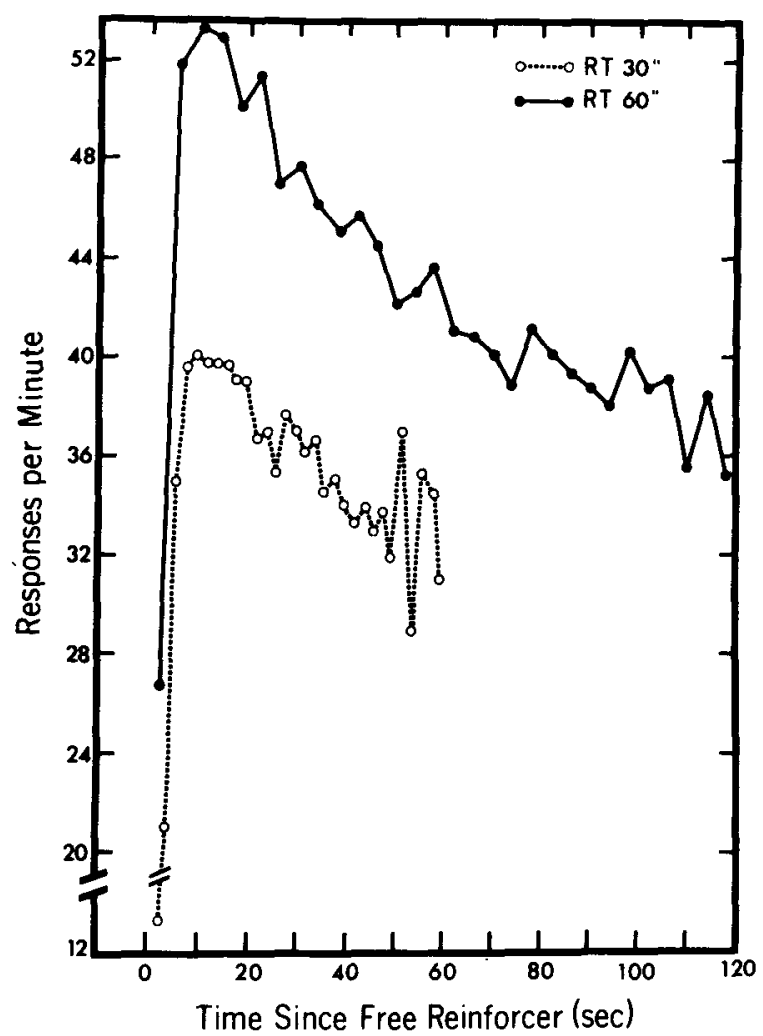

Figure 6. Rate of responding as a function of the time since the delivery of a free pellet during the RT schedules.

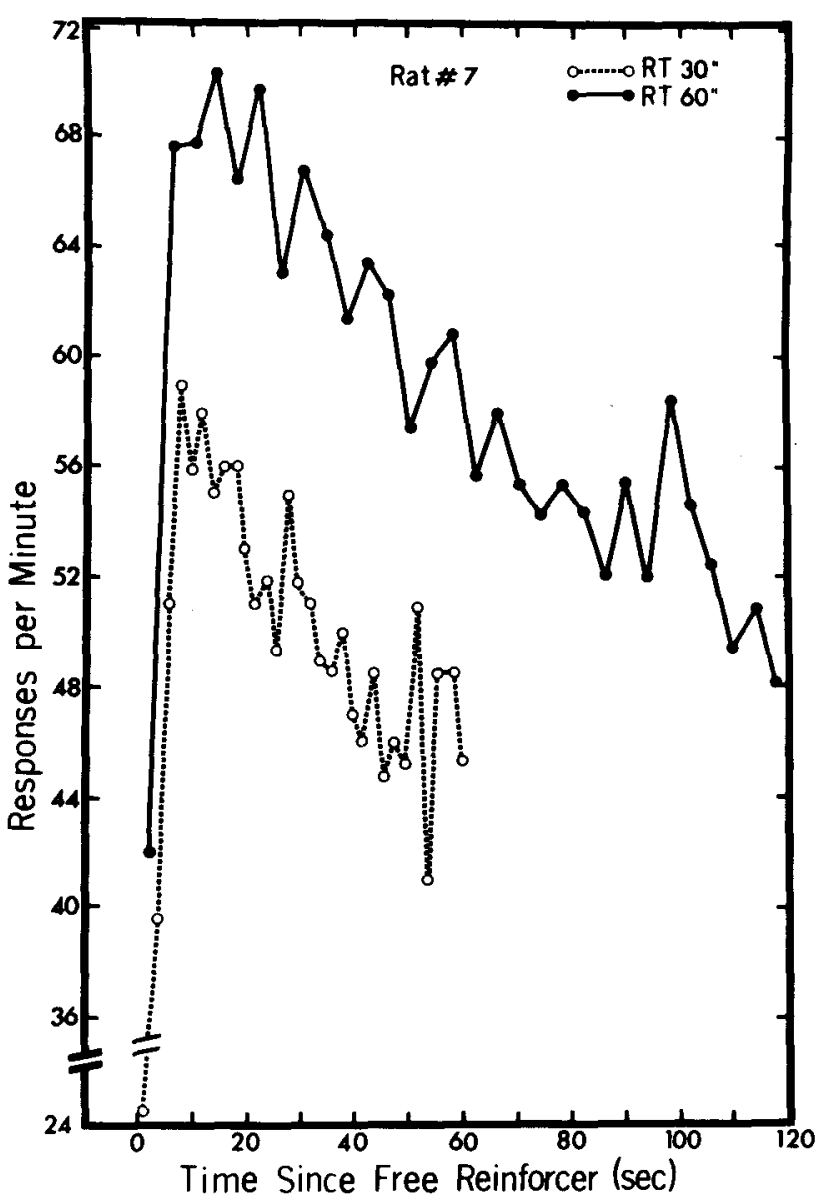

Figure 7. Rate of responding as a function of the time since the delivery of a free pellet during the RT schedules for Rat 7 .

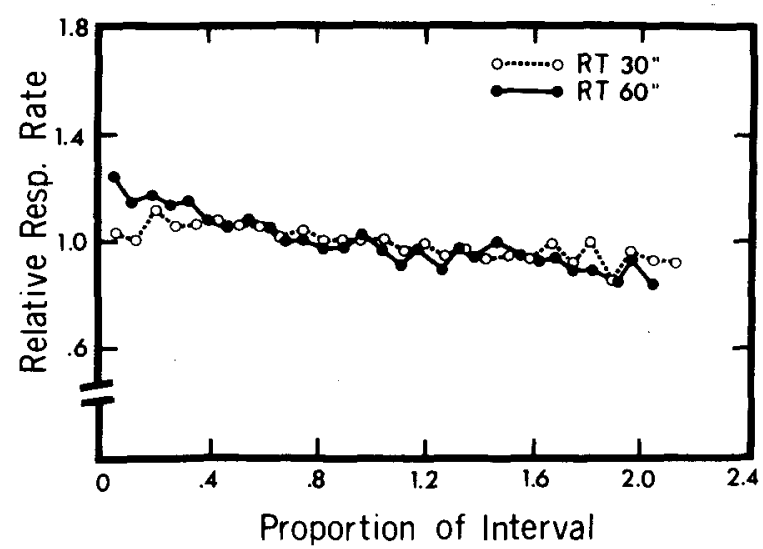

Figure 8. Momentary response rate relative to the mean response rate as a function of the proportion of the aperiodic interval between successive free pellets. 


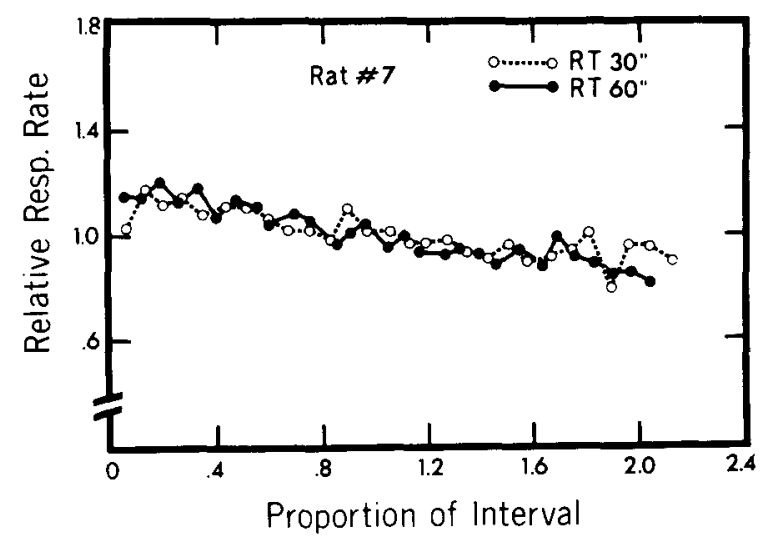

Figure 9. Momentary response rate relative to the mean response rate as a function of the aperiodic interval between successive free pellets for Rat 7.

contingent reinforcers was to inhibit leverpressing: increases in the rate of response-independent reinforcers, either according to the FT or the RT schedules, decreased responding. But there was also a local excitatory effect of such reinforcers upon leverpressing. Leverpressing increased to a level above its mean rate following the presentation of a free pellet (see Figures 2 and 6). Because, however, of the far greater inhibitory effect of the response-independent reinforcers, this excitatory effect was masked in Figure 1. Thus, both contingent reinforcers and noncontingent reinforcers have excitatory and inhibitory effects uporı responding. In the case of contingent reinforcers, the inhibitory effect is overshadowed by the predominant excitatory effect; in the case of noncontingent reinforcers, the excitatory effect is overshadowed by the predominant inhibitory effect.

It is interesting to note the similarity in the behavioral effects of free punishers and free reinforcers. Just as the amount of suppression increases as the rate of free punishers increases (Rachlin \& Herrnstein, 1969; Schuster \& Rachlin, 1968), so, too, does the amount of suppression increase as the rate of free reinforcers increases, as shown in the present study and those of Nevin (1974) and Rachlin and Baum (1972). Likewise, just as the behavioral aftereffect of free reinforcers is an increase in responding to well above the mean response rate, so, too, is there a burst of responding following the delivery of a free punisher (Church, Wooten, \& Matthews, 1970).

The temporal pattern of responding following the delivery of free reinforcers that was observed in this study may be related to various schedule-induced phenomena (e.g., Falk, 1971; Segal, 1972). For example, schedule-induced polydipsia and aggression, among others, are responses that are most probable following food presentation. Similarly, the excitatory effect of the free reinforcers in the present study was greatest just after free food delivery. It may be, then, that if the opportunity to drink or to attack had been available in the present study, such "emotionally induced behaviors" (Segal, 1972, p. 13) would have been observed instead of the burst of lever responding following free food delivery. That the time course of the behavioral aftereffect of free reinforcers follows a proportionality rule (Figures 4 and 8 ) suggests that, perhaps, the time course of schedule-induced phenomena may be dependent upon the proportion of the interval between successive important events.

\section{REFERENCES}

Catania, A. C. Concurrent performances: Reinforcement interaction and response independence. Journal of the Experimental Analysis of Behavior, 1963, 6, 253-263.

Catania, A. C. Concurrent operants. In W. K. Honig (Ed.), Operant behavior: Areas of research and application. New York: Appleton-Century-Crofts, 1966. Pp. 213-270.

Catania, A. C. Self-inhibiting effects of reinforcement. Journal of the Experimental Analysis of Behavior, 1973, 19, 517-526.

Church, R. M., Wooten, C. L., \& Matthews, T. J. Contingency between a response and an aversive event in the rat. Journal of Comparative and Physiological Psychology, 1970, 72, 476-485.

FALK, J. L. The nature and determinants of adjunctive behavior. Physiology and Behavior, 1971, 6, 577-588.

Nevin, J. A. Response strength in multiple schedules. Journal of the Experimental Analysis of Behavior, 1974, 21, 389-408.

RACHLIN, H., \& BAUM, W. M. Effects of alternate reinforcement: Does the source matter? Journal of the Experimental Analysis of Behavior, 1972, 18, 231-241.

Rachlin, H., \& Herrnstein, R. J. Hedonism revisited: On the negative law of effect. In B. A. Campbell \& R. M. Church (Eds.), Punishment and aversive behavior. New York: AppletonCentury-Crofts, 1969. Pp. 83-109.

SChuster, R., \& Rachlin, H. Indifference between punishment and free shock: Evidence for the negative law of effect. Journal of the Experimental Analysis of Behavior, 1968, 11, 777.786.

SEGAL, E. F. Induction and the provenance of operants. In R. M. Gilbert \& J. R. Millenson (Eds.), Reinforcement: Behavioral analyses. New York: Academic Press, 1972. Pp. 1-34.

ZeILER, M. D. Fixed and variable schedules of response-independent reinforcement. Journal of the Experimental Analysis of Behavior, 1968, 11, 405-414.

(Received for publication March 29, 1976; revision accepted August 11, 1976.) 